\title{
Hypercholesterolemia Can Be Improved by Stopping to Take Eggs and Milk
}

\author{
Hirohiko KoJıмA $^{1}$ \\ ${ }^{1}$ Oriental Clinic
}

\begin{abstract}
Changes of levels of serum lipids have been investigated on the condition of taking eggs and milk including their products for persons with hypercholesterolemia. In this study the levels of total cholesterol (TC), triglyceride (TG), high-density lipoprotein cholesterol (HDL-C) and low-density lipoprotein cholesterol (LDL-C) were compared at the annual health checks (ningen dock) of the previous year and of the current year. 289 subjects were divided into three groups, Group A of 175 subjects who took eggs and milk usually, Group B of 53 subjects who stopped to take them and Group $C$ of 61 subjects who did not take them as usual. In Group A, levels of TC, TG, HDL-C and LDL-C changed $250 \pm 23 \mathrm{mg} / \mathrm{d} l$ to $253 \pm 31$ $\mathrm{mg} / \mathrm{d} l, 140 \pm 95 \mathrm{mg} / \mathrm{d} l$ to $143 \pm 114 \mathrm{mg} / \mathrm{d} l, 65 \pm 16 \mathrm{mg} / \mathrm{d} l$ to $67 \pm 18 \mathrm{mg} / \mathrm{d} l$, and $158 \pm 26 \mathrm{mg} / \mathrm{d} l$ to $160 \pm 29 \mathrm{mg} / \mathrm{d} l$ respectively. In Group B, $262 \pm 31 \mathrm{mg} / \mathrm{d} l$ to $230 \pm 23 \mathrm{mg} / \mathrm{d} l, 132 \pm 64 \mathrm{mg} / \mathrm{d} l$ to $131 \pm 72 \mathrm{mg} / \mathrm{d} l, 69 \pm 17 \mathrm{mg} / \mathrm{d} l$ to $65 \pm 15 \mathrm{mg} / \mathrm{d} l$ and $165 \pm 30$ $\mathrm{mg} / \mathrm{d} l$ to $139 \pm 19 \mathrm{mg} / \mathrm{d} l$ respectively. In Group C, $255 \pm 22$ $\mathrm{mg} / \mathrm{d} l$ to $253 \pm 30 \mathrm{mg} / \mathrm{d} l, 167 \pm 130 \mathrm{mg} / \mathrm{d} l$ to $166 \pm 98 \mathrm{mg} / \mathrm{d} l$, $64 \pm 18 \mathrm{mg} / \mathrm{d} l$ to $64 \pm 17 \mathrm{mg} / \mathrm{d} l$ and $162 \pm 24 \mathrm{mg} / \mathrm{d} l$ to $159 \pm 31$ $\mathrm{mg} / \mathrm{d} l$ respectively. Levels of TC, HDL-C and LDL-C in Group B decreased significantly after stopping to take eggs and milk by $32 \pm 25 \mathrm{mg} / \mathrm{d} l(12 \%), 4 \pm 8 \mathrm{mg} / \mathrm{d} l(6 \%)$ and $26 \pm 26$ $\mathrm{mg} / \mathrm{d} l(16 \%)$ respectively. Also there were a linear correlation between TC and LDL-C levels $(y=0.7159 x-21.842, r=0.522)$ and an exponential correlation between TG and HDL-C levels $\left(y=203.74 x^{-0.2415}, r=0.2741\right)$.
\end{abstract}

Key Words Hypercholesterolemia, Eggs and Milk, Total Cholesterol, Serum Lipids

\section{INTRODUCTION}

The author has investigated how levels of serum lipids, especially of total cholesterol (TC), change for persons with hypercholesterolemia (TC levels are $220 \mathrm{mg} / \mathrm{d} l$ and more) who take eggs and milk including their products when they stop to take them through the two ways. One is that a cooperator returns the post card to write the levels of total cholesterol (TC) and triglyceride (TG) tested at his or her clinic after he or she stops to take eggs and milk for more than a week. And the levels at clinics are compared with the levels at the health checks (ningen dock). The other is that a co-operator responds to a questionnaire, that he or she takes eggs and milk, stops to take them, or does not take them, and levels of serum lipids at the annual health checks are compared with the levels of the previous year. The results of the former

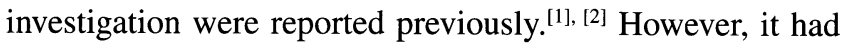

\footnotetext{
Received: September 14, 2006

${ }^{1}$ Address; Oriental Clinic, 1-chome 8-5, Imaike, Chikusa-ku, Nagoya, 464-8691 Japan. TEL: 81-052-741-5181, FAX: 81-052733-7100, E-mail:
}

defects that very few of those who took eggs and milk usually and did not take them as usual cooperated to the study. This investigation fills the defects and presents the changes of levels of serum lipids on the condition of taking eggs and milk, stopping to take them or not taking them.

\section{MATERIALS AND METHODS}

A few months before the annual health checks for the workers of five companies where the author was an occupational health doctor, questionnaires were delivered to company workers through the company's managers. The questionnaire was simple, yes or no of taking cholesterol-lowering drugs currently regardless of kind of drug, and which was yours, taking eggs and milk usually, stopping to take them and the period without eggs and milk, or not taking them as usual, similar to the previous investigation. ${ }^{[1]}$ Also some persons answered to the questionnaire when reviewing the results of their health checks including total cholesterol (TC), triglyceride (TG), high-density lipoprotein cholesterol (HDL-C), and low-density lipoprotein cholesterol (LDL-C). According to the responses subjects were divided into three groups, Group A of those who took eggs and milk usually, Group B of those who stopped to take them for more than a week and Group C of those who did not take them as usual. The division was the same as the previous investigation. ${ }^{[1]}$ Levels of TC, TG, HDL-C, and LDL-C of the annual health checks (the current year) were compared to the levels of the previous year about each group. The health checks were undergone definitely in over-night fasting. The results were presented as mean and standard deviation $(\mathrm{M} \pm \mathrm{SD})$. Statistical analysis was carried out by Student- $t$ test with two-sided test.

\section{RESULTS}

Of the responses from 2001 to 2004,289 subjects (166 males and 123 females, $52 \pm 9$ years old. 56 in 2001, 147 in 2002, 34 in 2003, and 52 in 2004) could be compared about the results of the health checks of the current year and the previous year, and also their TC levels of the previous year were $220 \mathrm{mg} / \mathrm{d} l$ and more. 175 subjects (90 males and 85 females, $53 \pm 9$ years old) belonged to Group A, 53 subjects ( 34 males and 19 females, $52 \pm 9$ years old) belonged to Group B and 61 subjects ( 46 males and 15 females, $51 \pm 9$ years old) belonged to Group C. The periods of stopping to take eggs and milk in Group B were eleven of a week, four of two weeks, two of two months, two of six months and six of a year. The others 

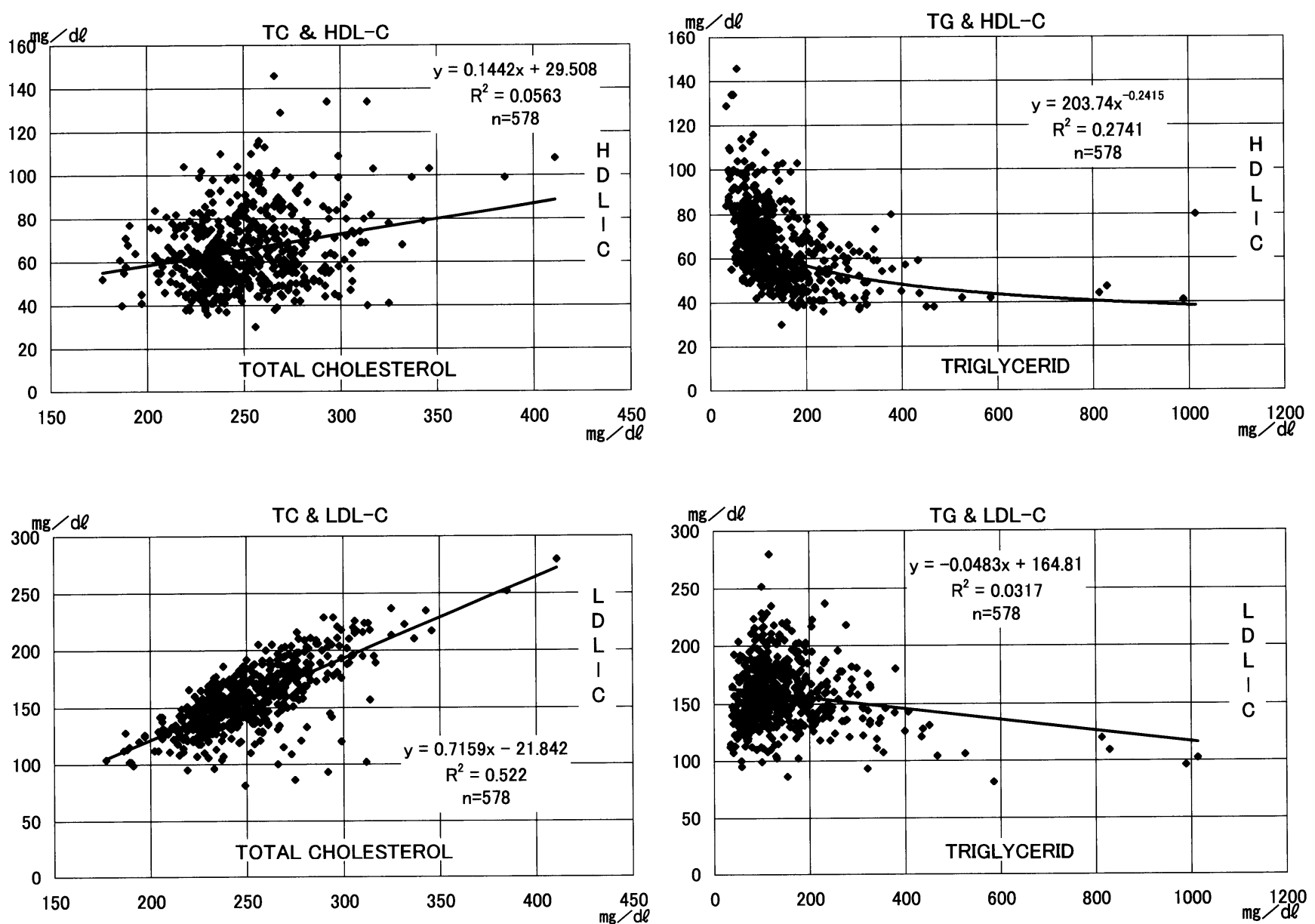

Fig. 1 Relationships between TC and HDL-C or LDL-C, and between TG and HDL-C or LDL-C.

TC levels correlate linearly with LDL-C levels (left lower) and TG levels correlate exponentially with HDL-C (right upper).

were for a month to a year. Sixteen subjects were taking cholesterol-lowering drugs, ten in group A, three in Group B and three in Group C.

In this study the range of levels of TC, TG, HDL-C and LDL-C was $177 \mathrm{mg} / \mathrm{d} l$ to $411 \mathrm{mg} / \mathrm{d} l, 34 \mathrm{mg} / \mathrm{d} l$ to 1,014 $\mathrm{mg} / \mathrm{d} l, 30 \mathrm{mg} / \mathrm{d} l$ to $109 \mathrm{mg} / \mathrm{d} l$ and $86 \mathrm{mg}$ to $280 \mathrm{mg} / \mathrm{d} l$ respectively. Concerned with the levels of serum lipids of all subjects, relationships of TC with HDL-C or LDL-C and of TG with HDL-C or LDL-C were shown in Fig. 1. There were a linear correlation between TC and LDL-C $(y=$ $0.7159 x-21.842, r=0.522$. left lower) and an exponential correlation between TG and HDL-C $\left(y=203.74 x^{-0.2415}\right.$, $r=0.2741$. right upper).

When the levels of serum lipids of the previous year and of the current year were compared, for 75 subjects (43\%) in Group A TC levels of the previous year were higher than of the current year, and for 94 subjects (54\%) were converse. The followings were 49 subjects $(92 \%)$ and 3 subjects $(6 \%)$ in Group B, 30 subjects (49\%) and 30 subjects (49\%) in Group $\mathrm{C}$ respectively. Table 1 showed also about levels of TG, HDL-C, and LDL-C.

The levels of serum lipids of the previous year, of the current year and of the difference (previous year minus current year) in Group A, Group B and Group C were showed in
Table 1 Difference of levels of serum lipids (previous year-current year. Number of subjects).

In Group B number of subjects are very high (92\%) whose TC levels of previous year are higher than those of current year.

\begin{tabular}{|c|c|c|c|c|c|}
\hline & & $\mathrm{TC}$ & TG & HDL-C & LDL-C \\
\hline Group A & + & $75(43 \%)$ & $80(46 \%)$ & $69(39 \%)$ & $81(46 \%)$ \\
\hline \multirow[t]{2}{*}{$n=175$} & - & $94(54 c$ & 91 & 96 & $89(51 \%)$ \\
\hline & 0 & 6 & 4 & 10 & 5 \\
\hline Group B & + & $49(92 \%)$ & $32(60 \%)$ & $33(62 \%)$ & $36(68 \%)$ \\
\hline \multirow[t]{2}{*}{$n=53$} & - & $3(6 \%)$ & $20(38 \%)$ & $17(32 \%)$ & $14(26 \%)$ \\
\hline & 0 & 1 & 1 & 3 & 3 \\
\hline Group C & + & $30(49 \%)$ & $26(43 \%)$ & $24(39 \%)$ & $30(49 \%)$ \\
\hline \multirow{2}{*}{$n=61$} & - & $30(49 \%)$ & $35(57 \%)$ & $33(54 \%)$ & $30(49 \%)$ \\
\hline & 0 & 1 & 0 & 4 & 1 \\
\hline
\end{tabular}

Group A: Subjects who took eggs and milk.

Group B: Subjects who stopped to take eggs and milk.

Group C: Subjects who did not take eggs and milk.

TC: total cholesterol.

TG: triglyceride.

HDL-C: HDL-choresterol.

LDL-C: LDL-choresterol.

$+:$ previous year $>$ current year.

- : previous year $<$ current year.

$0:$ previous year $=$ current year. 
Table 2 Levels of serum lipids in Group A, Group B and Group C.

In Group B, levels of TC, HDL-C and LDL-C decrease significantly after stopping to take eggs and milk.

Levels of serum lipids in Group A

\begin{tabular}{lcccc}
\hline & TC & TG & HDL-C & LDL-C \\
\hline Previous year & $250 \pm 23$ & $140 \pm 95$ & $65 \pm 16$ & $158 \pm 26$ \\
Current year & $253 \pm 31$ & $143 \pm 114$ & $67 \pm 18$ & $160 \pm 29$ \\
Difference & $-2 \pm 26$ & $-3 \pm 71$ & $-2 \pm 7$ & $-2 \pm 24$ \\
$\quad t$ & 1.206 & 0.689 & 3.067 & 1.321 \\
$\quad p$ & $n s$ & $n s$ & $p<0.01$ & $n s$ \\
\hline \multicolumn{5}{r}{} \\
\end{tabular}

Difference $=$ Previous year - Current year

Levels of serum lipids in Group B

\begin{tabular}{lcccc}
\hline & TC & TG & HDL-C & LDL-C \\
\hline Previous year & $262 \pm 31$ & $132 \pm 64$ & $69 \pm 17$ & $165 \pm 30$ \\
Current year & $230 \pm 23$ & $131 \pm 72$ & $65 \pm 15$ & $139 \pm 19$ \\
Difference & $32 \pm 25$ & $1 \pm 59$ & $4 \pm 8$ & $26 \pm 26$ \\
$\quad t$ & 9.258 & 0.166 & 3.474 & 7.345 \\
$\quad p$ & $\mathrm{p}<0.01$ & $n s$ & $p<0.01$ & $p<0.01$ \\
\hline \multicolumn{5}{r}{} \\
\end{tabular}

Difference $=$ Previous year - Current year

Levels of serum lipids in Group C

\begin{tabular}{ccccc}
\hline & TC & TG & HDL-C & LDL-C \\
\hline Previous year & $255 \pm 22$ & $167 \pm 130$ & $64 \pm 18$ & $162 \pm 24$ \\
Current year & $253 \pm 30$ & $166 \pm 98$ & $64 \pm 17$ & $159 \pm 31$ \\
Difference & $2 \pm 29$ & $1 \pm 85$ & $-1 \pm 9$ & $3 \pm 27$ \\
$\quad t$ & 0.450 & 0.106 & 0.684 & 0.879 \\
$p$ & $n s$ & $n s$ & $n s$ & $n s$ \\
\hline \multicolumn{1}{c}{} & & & $n=61, \mathrm{M} \pm \mathrm{SD}, \mathrm{mg} / \mathrm{d} l$
\end{tabular}

Difference $=$ Previous year - Current year

Table 2. In Group A, levels of TC, TG, HDL-C and LDL-C changed $250 \pm 23 \mathrm{mg} / \mathrm{d} l$ to $253 \pm 31 \mathrm{mg} / \mathrm{d} l, 140 \pm 95 \mathrm{mg} / \mathrm{d} l$ to $143 \pm 114 \mathrm{mg} / \mathrm{d} l, 65 \pm 16 \mathrm{mg} / \mathrm{d} l$ to $67 \pm 18 \mathrm{mg} / \mathrm{d} l$, and $158 \pm 26$ $\mathrm{mg} / \mathrm{d} l$ to $160 \pm 29 \mathrm{mg} / \mathrm{d} l$ respectively. TC, TG and LDL-C changed not significantly $(t=1.206,0.689$ and 1.321 respectively) and HDL-C increased by $2 \pm 7 \mathrm{mg} / \mathrm{d} l(3 \%)$ significantly $(p<0.01, t=3.067)$. In Group B, levels of TC, HDL-C and LDL-C decreased $262 \pm 31 \mathrm{mg} / \mathrm{d} l$ to $230 \pm 23 \mathrm{mg} / \mathrm{d} l$, $69 \pm 17 \mathrm{mg} / \mathrm{d} l$ to $65 \pm 15 \mathrm{mg} / \mathrm{d} l$ and $165 \pm 30 \mathrm{mg} / \mathrm{d} l$ to $139 \pm 19$ $\mathrm{mg} / \mathrm{d} l$ respectively and significantly $(p<0.01, t=9.258,3.474$ and 7.345 respectively), and the difference was $32 \pm 25 \mathrm{mg} / \mathrm{d} l$ $(12 \%), 4 \pm 8 \mathrm{mg} / \mathrm{d} l(6 \%)$ and $26 \pm 26 \mathrm{mg} / \mathrm{d} l(16 \%)$ respectively. But TG changed $132 \pm 64 \mathrm{mg} / \mathrm{d} l$ to $131 \pm 72 \mathrm{mg} / \mathrm{d} l$ not significantly $(t=0.166)$. In Group C, levels of TC, TG, HDL$\mathrm{C}$ and LDL-C changed $255 \pm 22 \mathrm{mg} / \mathrm{d} l$ to $253 \pm 30 \mathrm{mg} / \mathrm{d} l$, $167 \pm 130 \mathrm{mg} / \mathrm{d} l$ to $166 \pm 98 \mathrm{mg} / \mathrm{d} l, 64 \pm 18 \mathrm{mg} / \mathrm{d} l$ to $64 \pm 17$ $\mathrm{mg} / \mathrm{d} l$ and $162 \pm 24 \mathrm{mg} / \mathrm{d} l$ to $159 \pm 31 \mathrm{mg} / \mathrm{d} l$ respectively and not significantly $(t=0.450,0.106,0.684$ and 0.879 respectively).

\section{DISCUSSION}

Hypercholesterolemia is defined as $220 \mathrm{mg} / \mathrm{d} l$ and more of TC levels and hypertriglycedemia as $150 \mathrm{mg} / \mathrm{d} l$ and more of TG levels by the Committee of Guideline for Diagnosis and Treatment of Hyperlipidemias, Japan Atherosclerosis Soci-

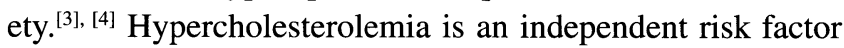
for coronary heart disease (CHD) and stroke related to atherosclerosis..$^{[3],[5]-[9]}$ Also the Japanese investigations in regard to TC levels presented the same relative risk of CHD as MRFIT, ${ }^{[6]}$ although mortality of CHD in Japan is a forth to a sixth compared to Western industrialized countries. ${ }^{[3], \text {, } 100]-[12]}$

The author reported previously that when persons with hypercholesterolemia stopped to take eggs and milk for more than a week, their TC levels decreased significantly. ${ }^{[1], ~[2] ~}$ However there were very few persons cooperated who took them usually and who did not take them as usual. ${ }^{[1]}$ This study showed that TC levels decreased significantly $262 \pm 31$ $\mathrm{mg} / \mathrm{d} l$ to $230 \pm 23 \mathrm{mg} / \mathrm{d} l$ (Table 2) for most (92\%) of them (Table 1) in Group B similar to the previous investigation ${ }^{[1],[2]}$ and levels of HDL-C and LDL-C also decreased significantly $69 \pm 17 \mathrm{mg} / \mathrm{d} l$ to $65 \pm 15 \mathrm{mg} / \mathrm{d} l$ and $165 \pm 30 \mathrm{mg} / \mathrm{d} l$ to $139 \pm 19$ $\mathrm{mg} / \mathrm{d} l$ respectively. However, in Group A and Group C, TC levels did not change significantly and neither levels of HDL$\mathrm{C}$ and LDL-C did except HDL-C in Group A. TG levels did not change significantly in three groups and did not affected by dietary eggs and milk (Table 2 ).

This investigation aimed only at change of TC levels and focused only on eggs and milk. From the data of all subjects of the previous year and the current year, there were a liner relationship between TC and LDL-C levels $(y=0.7159 x$ $-21.842, r=0.522)$ and an exponential relationship between TG and HDL-C levels $\left(y=203.74 x^{-0.2415}, r=0.2741\right)$ (Fig. 1). Therefore when TC levels decreased LDL-C levels decreased linearly and when TG levels decreased HDL-C levels increased exponentially.

This study has focused on taking eggs and milk, and not on other food rich-in cholesterol, calorie intake, life style, exercise, drinking and smoking which were also risk factors of CHD related to atherosclerosis and influenced TC levels. ${ }^{[3],[6],[7],[13]-[15]}$ The study showed that the levels of TC and LDL-C decreased significantly when stopping to take eggs and milk, and also HDL-C decreased unfavorably (Table 2).

The study comes to the conclusions that TC levels decrease significantly after persons who take eggs and milk stop to take them for more than a week and LDL-C and HDL-C levels decrease as well. Also there are a linear relationship between TC levels and LDL-C levels and an exponential relationship between TG levels and HDL-C levels. Therefore it might be necessary to reduce TG levels in order to increase HDL-C levels.

\section{ACKNOWLEDGEMENTS}

The author wishes to thank the workers of Aichi Chubu Water Supply Authority, Japan Sewage Works Agency, Nagoya City Disaster Prevention Management Corporation, Oriental Clinic and Oriental Industrial Health Associates Inc. for cooperating to the investigation. 


\section{REFERENCES}

[1] Kojima H: Effects of stopping to eat eggs and drink milk in Japanese with hypercholesterolemia. HEP 32: 359-363, 2005

[2] Kojima H: Hypercholesterolemia is improved by stopping to have eggs and milk. Ningen Dock 20: 42-45, 2005 (in Japanese with English summary)

[3] Investigation Committee of Guideline for Diagnosis and Treatment of Hyperlipidemias, Japan Atherosclerosis Society: Guideline for diagnosis and treatment of hyperlipidemias in adults. Doumyakukouka (Atherosclerosis) 25: 1-34, 1997 (in Japanese)

[4] Japan Atherosclerosis Society: Japan Atherosclerosis Society (JAS) guidelines for diagnosis and treatment of atherosclerotic cardiovascular diseases 1-55, 2000 (in Japanese)

[5] The Task Force on Cholesterol Issues, American Heart Association: The cholesterol facts. A summary of the evidence relating dietary facts, serum cholesterol, and coronary heart disease. A joint statement by the American Heart Association and the National Heart, Lung, and Blood Institute. Circulation 81: 1721-1733, 1990

[6] Kannel WB, Castelli WP, Gordon T, Mcnamara PM: Serum cholesterol, lipoproteins, and the risk of coronary heart disease. The Framingham study. Ann Intern Med 74: 1-12, 1971

[7] Stamler J, Wentworth D, Neaton DJ for the MRFIT Research Group: Is relationship between serum cholesterol and risk of premature death from coronary heart disease continuous and graded? Findings in 356222 primary screenees of the multiple risk factor intervention trial (MRFIT). JAMA 256: 28232828, 1986

[8] Wakugami K, Iseki K, Kimura Y, Okumura K, Ikeyama Y, Muratani H, Fukiyama K: Relationship between serum cholesterol and the risk of acute myocardial infarction in a screened cohort in Okinawa, Japan. Jpn Circ J 62: 7-14, 1998

[9] Sasaki J, Arakawa K, Iwashita M, Matsushita Y, Kono S. for the Kyushu lipid intervention study (KLIS) group: Reduction in serum total cholesterol and risks of coronary events and cerebral infarcton in Japanese men-The Kyusyu lipid intervention study-Circ J 67: 473-478, 2003

[10] Health and Welfare Statistics Association (Kousei Toukei Kyokai): Journal of health and welfare statistics (Kokumin eisei no doukou) 49: 35-78, 2002 (in Japanese)

[11] Saito I, Folsom AR, Aono H, Ozawa H, Ikebe T, Yamashita $\mathrm{T}$ : Comparison of fatal coronary heart disease occurrence based on population surveys in Japan and the USA. Intern $\mathbf{J}$ Epidemiol 29: 837-844, 2000

[12] Verschuen WM, Jacobs DR, Bloemberg BM, Kromhout D, Menotti A, Aravanis C, Blackburn H, Buzina R, Dontas AS, Fidanza F, Karvonen MJ, Nedeljkovic S, Nissinen A, Toshima H: Serum total cholesterol and long-term coronary heart disease mortality in different cultures. Twenty-five-year follow-up of the seven countries study. JAMA 274: 131-136, 1995

[13] Kodama K, Sasaki H, Shimizu Y: Trend of coronary heart disease and its relationship to risk factors in a Japanese population: A 26-year follow-up, Hiroshima/Nagasaki study. Jap Circ J 54: 414-421, 1990

[14] Wood P, Stefanick M, Williams P, Haskell W: The effects on plasma lipoproteins of a prudent weight-reducing diet, with or without exercise, in overweight men and women. N Eng J Med 325: 461-466, 1991

[15] Yamamoto R, Kawamura T, Wakai K, Ichihara Y, Anno T, Mizuno Y, Yokoi M, Ohta T, Iguchi A, Ohno Y: Favorable life-style modification and attenuation of cardiovascular risk factors. Jpn Circ J 63: 184-188, 1999 